\title{
FRONT-HAND-PUNCH SPEED IMPROVEMENT EXPERIMENTAL METHODOLOGY IN KARATE
}

\author{
Radoslav Penov, Milen Chalakov \\ National Sports Academy "Vassil Levski"
}

\begin{abstract}
This article presents the development of an experimental methodology that aims to improve the speed of the front-hand punch in karate. The rationale behind developing this methodology is that the speed of the front-hand punch in karate is one of the most important criteria for the successful defeat of the opponent. In addition, the front-hand punch is one of the most commonly used punches during matches. The objective that we set was to study the effect of the application of the methodology we developed for the purpose of improving the speed of the front-hand punch (Kizami Tsuki) in karate. To accomplish this study, we used a computerized video system to register and analyze the speed of karate punches performed by the participants in the experiment. The results regarding the speed of the straight-hand punch were measured in the same way in order to provide identical conditions. Input data was processed by means of applied software for kinematic analysis. To prove the credibility of the registered data, we used statistical analysis methodology. We hope that by presenting our methodology in this article, more coaches will begin to use modern tools and methods in order to improve the quality of training in karate.
\end{abstract}

Key words: methodology, karate, punch, front hand, speed

\section{INTRODUCTION}

There is a large number of hand punches used in modern karate, as these punches are also specific for this sport. These punches are aimed at three body levels: low, middle, and high (Gedan, Chudan, and Jodan). Using these punches in high maneuverability and dynamics demands highly specialized technical preparation and physical and psychical stability on the competitor's part (Bishop, 1989, Higaonna, 1985).

Hand punches are easier to perform than kicks because they allow for keeping balance, which provides a more stable support. If the technique is performed correctly, its power, speed, precision, and the damage on the opponent cannot be denied (Habersetzer 1998, Bogdanov, Ivanov 1972).

Karate is a successful fighting sport, because the punches performed during a fight are with high speed, power and accuracy
(Chaabène et. al, 2015). A prerequisite for the high quality of assault technique is the exercises practiced in karate, which increase the speed of the punches (Marqueset. al., 2013). The most commonly used offensive techniques in karate used during a fight are strikes such as (gyakuzuki is the reverse punch, kizami zuki is the jab punch and oi zuki is the lunge punch) and the kicks (maegeri is the front kick and mawashi geri is the semicircular kick) (Chaabène et. al, 2014). But punches are more likely to be applied because they offer better opportunities for successful striking (Marques, 2013).

According to Marquez Junior (Marques, 2014), the speeds which karate hand-fighting techniques are performed, as well as the fact that they are executed with a person facing the opponent, increase the chance of successful strikes.

According to Nakayama (Nakayma, 2012), 
speed is particularly important for offensive techniques in karate because the high-speed attack is difficult to defend.

After a systematic review of the speed of punch techniques in karate, we found that it is of paramount importance to the fighter who must choose the best attack during the bout. (Barbanti, 2010)

There is little information on this topic (Marques, 2012) and there is no systematic review of velocity of the offensive techniques of the karate in combat sports literature (Franchini, Del Vecchio, 2011)

In order to improve and perfect karate techniques, trainees need to perform multiple repetitions with maximum concentration and dedication. This, however, will not be enough if the training does not rely on proper physical and physiological principles (Marques, 2014).

\section{Study Objective:}

Studying the effects of the application of the methodology for targeted improvement of the speed of the front-hand punch (Kizami Tsuki) in karate.

\section{Study Goals:}

To reveal the importance of the speed of the punch as inherent to technical mastery in karate-do.

To develop a methodology specifically aimed at developing the speed of the punch.

To analyze the effect of using this specific training method.

\section{METHODOLOGY}

The study was conducted by means of a computerized video system for registration and analysis of the karate punch speed. Ten male competitors from National Sports Academy "Vassil Levski" took part in the study. The average age of the participants was 22 years, ranging from 19 to 26. Ranks in karate varied from $5^{\text {th }} \mathrm{Kyu}$ to $1^{\text {st }} \mathrm{Dan}$.

Competitors (surveyed):

1. Ivaylo S. - Republican champion for 2017, 3 kyu, brown belt.

2. Denis N. - Republican champion for 2017, 3 dan, black belt.

3. Martin M. - Republican champion 2018, 2 dan, black belt.

4. Emre K. - third place Republican Championship 2017, blue belt.

5. Nikolay N. - Republican champion Team 2017, 5 kyu, blue belt.

6. Antoine T. - Republican champion for 2014, 1 dan, black belt.

7. Stancho S. - Republican champion 2017, 1 dan, black belt.

8. Vadim G. - Republican champion 2016, 3 dan, black belt.

9. Miroslav M. - Republican champion 2012, 1 dan, black belt.

10. Georgi A. - Republican champion 2013, 1 dan, black belt.

To complete the tasks, the participants were divided into two groups: a test group and a control group. Both groups delivered a straight-hand punch onto the target, and the results achieved were diligently recorded. We applied the specialized methodology aiming to develop the speed of the front hand punch onto the test group for a period of five months. The methodology applied is shown in Table 2 and Table 3.

The distribution of the persons surveyed by us in two groups is shown in Table 1. 
Table 1. Groups organization

\begin{tabular}{cc}
\hline Control group & Test group \\
\hline I. S. & A. T. \\
D. N. & M. M. \\
N. N. & V. G. \\
S. S. & E. K. \\
G. A. & M. M. \\
\hline
\end{tabular}

Table 2. Applied methodology for the test group:

\begin{tabular}{|c|c|c|c|c|c|}
\hline Months & I & II & III & IV & V \\
\hline \multicolumn{6}{|l|}{$\begin{array}{l}\text { Mandatory exercises used } \\
\text { to build speed for the } \\
\text { "Kizami tsuki" hand-punch }\end{array}$} \\
\hline 1. 10-Meter spring / reps. & dosage & dosage & dosage & dosage & dosage \\
\hline Week 1 & $4 \mathrm{X} 10$ & $6 \times 10$ & $10 \mathrm{X} 10$ & $12 X 10$ & $10 \mathrm{X} 10$ \\
\hline Week 2 & $6 \mathrm{X} 10$ & $8 X 10$ & $12 \times 10$ & $10 \mathrm{X} 10$ & $8 X 10$ \\
\hline Week 3 & $6 \mathrm{X} 10$ & $10 \times 10$ & $12 \mathrm{X} 10$ & $10 \mathrm{X} 10$ & $8 X 10$ \\
\hline Week 4 & $8 X 10$ & $10 \times 10$ & $12 \times 10$ & $10 \mathrm{X} 10$ & $8 X 10$ \\
\hline \multicolumn{6}{|l|}{ 2. 20-Meter spring / reps. } \\
\hline Week 1 & $2 \mathrm{X} 20$ & $6 \times 20$ & $9 X 20$ & $10 \times 20$ & $8 X 20$ \\
\hline Week 2 & $4 \mathrm{X} 30$ & $7 X 20$ & $10 \mathrm{X} 20$ & $8 X 20$ & $6 \times 20$ \\
\hline Week 3 & $6 \times 20$ & $9 \times 20$ & $10 \mathrm{X} 20$ & $8 X 20$ & $6 \times 20$ \\
\hline Week 4 & $7 \mathrm{X} 20$ & $9 \times 20$ & $10 \mathrm{X} 20$ & $8 X 20$ & $6 \times 20$ \\
\hline \multicolumn{6}{|l|}{ 3. 30-Meter spring / reps. } \\
\hline Week 1 & $6 \times 30$ & $7 X 30$ & $8 \times 30$ & $7 X 30$ & $6 \times 30$ \\
\hline Week 2 & $4 X 30$ & $6 \times 30$ & $6 \times 30$ & $6 \times 30$ & $4 \mathrm{X} 30$ \\
\hline Week 3 & $2 \times 30$ & $3 \times 30$ & $4 \times 30$ & $3 \mathrm{X} 30$ & $2 \times 30$ \\
\hline Week 4 & $2 \times 30$ & $3 \times 30$ & $4 \times 30$ & $3 \times 30$ & $2 \times 30$ \\
\hline \multicolumn{6}{|l|}{ 4. 50-Meter spring / reps. } \\
\hline Week 1 & $2 \times 50$ & $3 X 50$ & $4 X 50$ & $3 X 50$ & $2 X 50$ \\
\hline Week 2 & $3 X 50$ & $4 X 50$ & $5 X 50$ & $4 X 50$ & $3 X 50$ \\
\hline Week 3 & $4 X 50$ & $5 \times 50$ & $6 \times 50$ & $5 X 50$ & $4 X 50$ \\
\hline Week 4 & $4 X 50$ & $5 \times 50$ & $6 \times 50$ & $5 \times 50$ & $4 X 50$ \\
\hline \multicolumn{6}{|l|}{ 5. 100-Meter spring / reps. } \\
\hline Week 1 & $3 \mathrm{X} 100$ & $4 \mathrm{X} 100$ & $5 \times 100$ & $4 \mathrm{X} 100$ & $3 \times 100$ \\
\hline Week 2 & $2 \times 100$ & $3 \mathrm{X} 100$ & $4 \times 100$ & $3 \times 100$ & $2 \mathrm{X} 100$ \\
\hline Week 3 & $2 \times 100$ & $2 \mathrm{X} 100$ & $3 X 100$ & $2 \times 100$ & $2 \times 100$ \\
\hline Week 4 & $1 \mathrm{X} 100$ & $1 \mathrm{X} 100$ & $2 \times 100$ & $1 \mathrm{X} 100$ & $1 \mathrm{X} 100$ \\
\hline \multicolumn{6}{|l|}{$\begin{array}{l}\text { 6. Shuttles 3-6-9 meters/ } \\
\text { reps. }\end{array}$} \\
\hline Week 1 & $2 \times 3-6-9$ & $3 \times 3-6-9$ & $4 \times 3-6-9$ & $5 \times 3-6-9$ & $4 \times 3-6-9$ \\
\hline Week 2 & $3 \times 3-6-9$ & $4 \times 3-6-9$ & $5 \times 3-6-9$ & $4 \times 3-6-9$ & $3 \times 3-6-9$ \\
\hline Week 3 & $3 \times 3-6-9$ & $4 \times 3-6-9$ & $5 \times 3-6-9$ & $4 \times 3-6-9$ & $3 \times 3-6-9$ \\
\hline Week 4 & $3 \times 3-6-9$ & $4 \times 3-6-9$ & $5 \times 3-6-9$ & $4 \times 3-6-9$ & $3 \times 3-6-9$ \\
\hline
\end{tabular}


7. "Kizami tsuki" hand-

punch 10 seconds/ reps.

$\begin{array}{llllll}\text { Week } 1 & 2 \mathrm{X} 10 & 2 \mathrm{X} 10 & 3 \mathrm{X} 10 & 4 \mathrm{X} 10 & 3 \mathrm{X} 10 \\ \text { Week } 2 & 2 \mathrm{X} 10 & 3 \mathrm{X} 10 & 4 \mathrm{X} 10 & 3 \mathrm{X} 10 & 2 \mathrm{X} 10 \\ \text { Week } 3 & 2 \mathrm{X} 10 & 3 \mathrm{X} 10 & 4 \mathrm{X} 10 & 3 \mathrm{X} 10 & 2 \mathrm{X} 10 \\ \text { Week } 4 & 2 \mathrm{X} 10 & 3 \mathrm{X} 10 & 4 \mathrm{X} 10 & 3 \mathrm{X} 10 & 2 \mathrm{X} 10\end{array}$

8. Kizami tsuki handpunch and change of guard

10 seconds / reps.

\begin{tabular}{llllll} 
Week 1 & $2 \mathrm{X} 10$ & $2 \mathrm{X} 10$ & $3 \mathrm{X} 10$ & $4 \mathrm{X} 10$ & $3 \mathrm{X} 10$ \\
Week 2 & $2 \mathrm{X} 10$ & $3 \mathrm{X} 10$ & $4 \mathrm{X} 10$ & $3 \mathrm{X} 10$ & $2 \mathrm{X} 10$ \\
Week 3 & $2 \mathrm{X} 10$ & $3 \mathrm{X} 10$ & $4 \mathrm{X} 10$ & $3 \mathrm{X} 10$ & $2 \mathrm{X} 10$ \\
Week 4 & $2 \mathrm{X} 10$ & $3 \mathrm{X} 10$ & $4 \mathrm{X} 10$ & $3 \mathrm{X} 10$ & $2 \mathrm{X} 10$ \\
\hline
\end{tabular}

9. "Kizami tsuki" hand-

punch and a feint tech-

nique for Mawashi geri 10

seconds / reps.

$\begin{array}{llllll}\text { Week } 1 & 2 \mathrm{X} 10 & 2 \mathrm{X} 10 & 3 \mathrm{X} 10 & 4 \mathrm{X} 10 & 3 \mathrm{X} 10 \\ \text { Week } 2 & 2 \mathrm{X} 10 & 3 \mathrm{X} 10 & 4 \mathrm{X} 10 & 3 \mathrm{X} 10 & 2 \mathrm{X} 10 \\ \text { Week } 3 & 2 \mathrm{X} 10 & 3 \mathrm{X} 10 & 4 \mathrm{X} 10 & 3 \mathrm{X} 10 & 2 \mathrm{X} 10 \\ \text { Week } 4 & 2 \mathrm{X} 10 & 3 \mathrm{X} 10 & 4 \mathrm{X} 10 & 3 \mathrm{X} 10 & 2 \mathrm{X} 10\end{array}$

10. Shot-putting a heavy

ball against a wall punch-

bag reps.

Week 1

Week 2

$\begin{array}{lllll}2 \times 10 & 3 \times 10 & 4 X 10 & 5 \times 10 & 4 X 10 \\ 3 \times 10 & 4 X 10 & 5 X 10 & 4 X 10 & 3 \times 10 \\ 3 \times 10 & 4 X 10 & 5 X 10 & 4 X 10 & 3 \times 10 \\ 3 \times 10 & 4 X 10 & 5 X 10 & 4 \times 10 & 3 \times 10\end{array}$

Week 3
Week 4
11. "Kizami tsuki" hand-
punchagainst elastic resis-

punchagainst elastic resis-

tance.

\begin{tabular}{|c|c|c|c|c|c|}
\hline Week 1 & $3 \mathrm{X} 10$ & $4 \mathrm{X} 10$ & $5 \times 10$ & $6 \times 10$ & $5 \times 10$ \\
\hline Week 2 & $4 X 10$ & $5 \times 10$ & $6 \times 10$ & $5 \times 10$ & $4 \times 10$ \\
\hline Week 3 & $4 \mathrm{X} 10$ & $5 \times 10$ & $6 \times 10$ & $5 \times 10$ & $4 \times 10$ \\
\hline Week 4 & $4 \mathrm{X} 10$ & $5 \times 10$ & $6 \times 10$ & $5 \times 10$ & $4 \times 10$ \\
\hline
\end{tabular}

Description of exercises used by the test group for the development of speed when performing "Kizami tsuki" hand-punch.

10-Meter sprint - This exercise aims to develop the quality of speed. It is performed from a low-start position upon the coach's signal at the maximum speed possible. The exercise is performed in series with a 30 -second break between the series. The exercise is performed after a very good general and special warm- up. It is evident from the table with the dosage of this exercise that from January to March the number of the series increases and from April to May the overall amount decreases.

20-Meter sprint -This exercise aims to develop the quality of speed. It is performed from a low-start position upon the coach's signal at the maximum speed possible. The exercise is performed in series with 30-45 seconds of break between the series. The exercise is 
performed after a very good general and special warm-up. From the table with the dosage of this exercise, it is evident that from January to March the number of the series increases and from April to May the overall amount decreases.

30-Meter sprint - This exercise aims to develop the quality of speed. It is performed from a low-start position upon the coach's signal at the maximum speed possible. The exercise is performed in series with 45 -seconds to 1-minute breaks between the series. The exercise is performed after a very good general and special warm-up. From the table with the dosage of this exercise, it is evident that during the first week of each month this exercise is done in more series and the number of series decreases in each of the following weeks.

50-Meter sprint - This exercise aims to develop the quality of speed. It is performed from a low-start position upon the coach's signal at the maximum speed possible. The exercise is performed in series with a 1-minute break between the series. The exercise is performed after a very good general and special warm-up. It is evident from the table with the dosage of this exercise that from January to March the number of the series increases and from April to May the overall number decreases.

100-Meter sprint - This exercise aims to develop the quality of speed. It is performed from a low-start position upon the coach's signal at the maximum speed possible. The exercise is performed in series with 1,5-minute breaks between the series. The exercise is performed after a very good general and special warm-up. From the table with the dosage of this exercise, it is evident that during the first week of each month this exercise is done in more series and the number of series decreases in each of the following weeks.

3-6-9 Shuttle running. This exercise of shuttle running is performed from low-start position upon the coach's signal. The athlete sprints from the starting point to the 3-meter mark, then sprints back to the starting point, sprints to the 6-meter mark, sprints back to the starting point, and sprints to the 9-meter marker and back. This exercise develops speed and agility. It is performed after a very good general and special warm-up. The break between the series is 2 minutes. It is evident from the table with the dosage of this exercise that from January to March the number of the series increases and from April to May the overall number decreases.

"Kizami tsuki" hand-punch for $10 \mathrm{sec}$ onds - This is one of the specialized exercises for developing speed of the upper limbs, and more particularly, it is the straight punch with the front hand. This exercise is performed in pairs, as one participant holds a pinching pad at the level of the head and the other participant performs 'Kizami tsuki" and aims to perform as many techniques as possible within the 10 -second interval. The coach measures the time and signals the beginning and the end of the interval. The intermission between the series is 1 minute. From the table with the dosage of this exercise, it is evident that the number of the series increases from January to March and that it decreases from April to May.

"Kizami tsuki" hand-punch with change of guard for 10 seconds - This is a specialized exercise for developing speed of both the upper and the lower limbs. This exercise is performed in pairs, as one participant holds a pinching pad at the level of the head and the other participant performs "Kizami tsuki", then switches the guard position and the punching hand and performs "Kizami tsugki" again from the newly assumed guard. The athlete aims to perform as many techniques as possible within the 10 -second interval. The coach measures the time and signals the beginning and the end of the interval. The inter- 
mission between the series is 1 minute. From the table with the dosage of this exercise, it is evident that the number of the series increases from January to March and that it decreases from April to May.

"Kizami tsuki" hand-punch and a feint technique for "Mawashi geri" - This is a specialized exercise for developing speed of both the upper and the lower limbs. This exercise is performed in pairs, as one participant holds a pinching pad at the level of the head and the other participant performs a feint technique for "Mawashi" Geri after which performs "Kizami tsuki", then switches the guard position and the punching hand. The athlete aims to perform as many techniques as possible within the 10-second interval. The coach measures the time and signals the beginning and the end of the interval. The intermission between the series is 1 minute. From the table with the dosage of this exercise, it is evident that the number of the series increases from January to March and that it decreases from April to May.

Shot-putting a heavy ball against a wall punch-bag - This exercise aims to develop the explosive power of the upper limbs. It is performed after a very good general and special warm-up. The weight of the heavy ball is 3 kilograms. The athlete assumes "guard" position facing the wall punch-bag at a 3-meter distance and shot-puts the heavy ball towards the punch-bag. It is essential the push should resemble biomechanically the "Kizami tsuki" pinch as much as possible. The intermission between the series is 30 seconds. From the table with the dosage of this exercise, it is evident that the number of the series increases from January to March and that it decreases from April to May.

"Kizami tsuki" hand-punchagainst elastic resistance - This exercise aims to develop the explosive power of the upper limbs. It is performed after a very good general and special warm-up. An elastic band is used to provide elastic resistance. The athlete stands with his/ her back towards a horizontal bar or a wall bar, to which one end of the elastic band is tied. The athlete holds the other end of the elastic band with the punching hand and performs "Kizami tsuki". The exercise is repeated 10 times at maximum speed and the intermission between the series is 1 minute. From the table with the dosage of this exercise, it is evident that the number of the series increases from January to March and that it decreases from April to May.

Table 3. Applied methodology for control group:

\begin{tabular}{|c|c|c|c|c|c|}
\hline Months & I & II & III & IV & V \\
\hline \multicolumn{6}{|c|}{$\begin{array}{l}\text { Exercises used to build } \\
\text { speed for the "Kizami tsuki" } \\
\text { hand-punch in the control } \\
\text { group }\end{array}$} \\
\hline \multicolumn{6}{|c|}{ 1. 50 -meter sprint } \\
\hline Week 1 & $2 X 50$ & $4 X 50$ & $5 \times 50$ & $6 X 50$ & $7 \times 50$ \\
\hline Week 2 & $3 X 50$ & $5 X 50$ & $6 \times 50$ & $7 X 50$ & $8 \times 50$ \\
\hline Week 3 & $4 \mathrm{X} 40$ & $5 X 50$ & $6 \times 50$ & $7 X 50$ & $8 \times 50$ \\
\hline Week 4 & $4 X 50$ & $5 X 50$ & $6 X 50$ & $7 X 50$ & $8 \times 50$ \\
\hline
\end{tabular}




\begin{tabular}{|c|c|c|c|c|c|}
\hline \multicolumn{6}{|c|}{ 2. Standing long jump } \\
\hline Week 1 & $2 \times 10$ & $3 \times 10$ & $4 \times 10$ & $5 \times 10$ & $6 \times 10$ \\
\hline Week 2 & $3 \times 10$ & $4 \times 10$ & $5 \times 10$ & $6 \times 10$ & $7 \times 10$ \\
\hline Week 3 & $3 \times 10$ & $4 \times 10$ & $5 \times 10$ & $6 \times 10$ & $7 \times 10$ \\
\hline Week 4 & $3 \times 10$ & $4 \times 10$ & $5 \times 10$ & $6 \times 10$ & $7 \times 10$ \\
\hline \multicolumn{6}{|c|}{$\begin{array}{l}\text { 3. "Kizami tsuki" hand- } \\
\text { punch - maximum number } \\
\text { per } 20 \text { seconds }\end{array}$} \\
\hline Week 1 & $2 \mathrm{X} 20$ & $3 \mathrm{X} 20$ & $4 \times 20$ & $5 \times 20$ & $6 \times 20$ \\
\hline Week 2 & $2 \times 20$ & $3 \mathrm{X} 20$ & $4 \times 20$ & $5 \times 20$ & $6 \times 20$ \\
\hline Week 3 & $2 \mathrm{X} 20$ & $3 \mathrm{X} 20$ & $4 \mathrm{X} 20$ & $5 \times 20$ & $6 \times 20$ \\
\hline Week 4 & $2 \times 20$ & $3 \mathrm{X} 20$ & $4 X 20$ & $5 \times 20$ & $6 \times 20$ \\
\hline \multicolumn{6}{|c|}{ 4. 6-9-12 Shuttle running } \\
\hline Week 1 & $2 \times 6-9-12$ & $3 \times 6-9-12$ & $4 X 6-9-12$ & $5 \times 6-9-12$ & $6 \times 6-9-12$ \\
\hline Week 2 & $2 X 6-9-12$ & $3 \times 6-9-12$ & $4 \times 6-9-12$ & $5 \times 6-9-12$ & $6 \times 6-9-12$ \\
\hline Week 3 & $2 X 6-9-12$ & $3 \times 6-9-12$ & $4 X 6-9-12$ & $5 \times 6-9-12$ & $6 \times 6-9-12$ \\
\hline Week 4 & 2X6-9-12 & $3 \times 6-9-12$ & 4X6-9-12 & $5 \times 6-9-12$ & $6 \times 6-9-12$ \\
\hline
\end{tabular}

Description of exercises used by the control group for the development of speed when performing "Kizami tsuki" hand-punch.

50-Meter sprint - This exercise aims to develop the quality of speed. It is performed from a low-start position upon the coach's signal at the maximum speed possible. The exercise is performed in series with a 1-minute break between the series. The exercise is performed after a very good general and special warm-up. It is evident from the table with the dosage of this exercise that from January to May the number of the series increases.

Standing long jump - This exercise develops the explosive power of the lower limbs. It is performed after a very good general and special warm-up. One series includes 10 repetitions. The intermission between series is 1 minute. The athlete performs a long jump from the starting position, then faces backwards and performs another long jump towards the staring position. A total of 10 repetitions are performed. As the dosage table indicates for this exercise, from January to May the number of the series increases.
"Kizami tsuki" hand-punch - maximum number of repetitions for 20 seconds. This is a specialized exercise for developing speed of both the upper and the lower limbs. This exercise is performed in pairs, as one participant holds a pinching pad at the level of the head and the other participant performs "Kizami tsuki", then switches the guard position and the punching hand and performs "Kizami tsugki" again from the newly assumed guard. The athlete aims to perform as many repetitions as possible in 20 seconds. The coach measures the time and signals the beginning and the end of the interval. The intermission between the series is 2 minutes. From the table with the dosage of this exercise, it is evident that the number of the series increases from January to May.

6-9-12 Shuttle running. This exercise is performed from low-start position upon the coach's signal. The athlete sprints from the starting point to the 6-meter mark, then sprints back to the starting point, sprints to the 9-meter mark, sprints back to the starting point, and sprints to the 12-meter marker and back. This 
exercise develops speed and agility. It is performed after a very good general and special warm-up. The break between the series is 3 minutes. It is evident from the dosage table about this exercise that from January to May the number of the series increases.

The results received regarding the speed straight-hand punch of both groups were measured in identical ways in order to provide the same test conditions for both groups. The data received were discussed with specialists in order to eliminate possible mistakes. The speed of the punch was recorded by means of Sony PJ740 video camera, at 50 frames per second. The camera was positioned perpendicularly to the sagittal axis of the punches, and the point of view was at the height of the punches. The video recordings were further processed by Kinovea video computer software for cinematic analysis. Only attempts that met the requirements for the speed of the punch were analyzed. The data were further analyzed and averaged with regard of the phase periods (Rathee, Magnes, Davis, 2014). The results received through video recording were processed by means of statistical method - descriptive statistics:

Average values of indicators $-\mathrm{X}$ mean. The sample mean formula is: $\overline{\mathrm{x}}=\left(\sum \mathrm{xi}\right) / \mathrm{n}$

$\overline{\mathrm{x}}$ just stands for the "sample mean";

$\Sigma$ means "add up";

xi "all of the x-values";

$n$ means "the number of items in the sample".

Standard deviation - S. The formula for standard deviation (SD) is

$$
s=\sqrt{\frac{\sum(x-\bar{x})^{2}}{n-1}}
$$

Where $\Sigma$ means "sum of", $\mathrm{X}$ is a value in the data set, $\mu$ is the mean of the data set, and $\mathrm{N}$ is the number of data points.

Coefficient of variation - V\%. The formula for the coefficient of variation is:

Coefficient of Variation $=($ Standard Deviation / Mean) $* 100$.

In symbols: $\mathrm{CV}=(\mathrm{SD} / \mathrm{x}$ mean $) * 100$.

\section{RESULTS}

The punch-speed in karate depends on the correct performance of all phases included in their execution. Figure 1 illustrates all the phases of the punch that were videotaped. Eventually, all punches performed were compared with their correct execution.

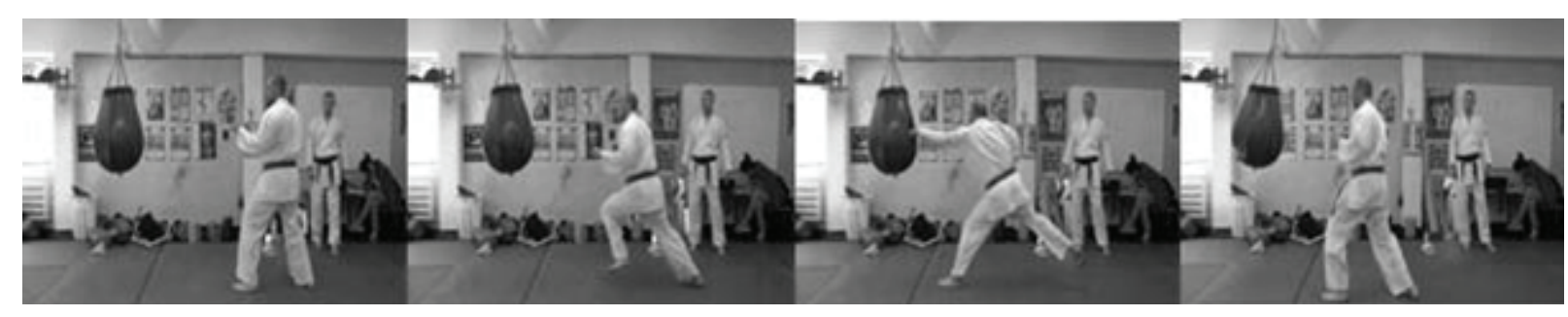

Figure 1. Punch phases

After the first and the second measurements, regarding the speed parameters of the punch, we received the following results for the control group. The results are shown in Figure 2 and Figure 3. 


\section{Results of first measurement in meters per second for the control group}

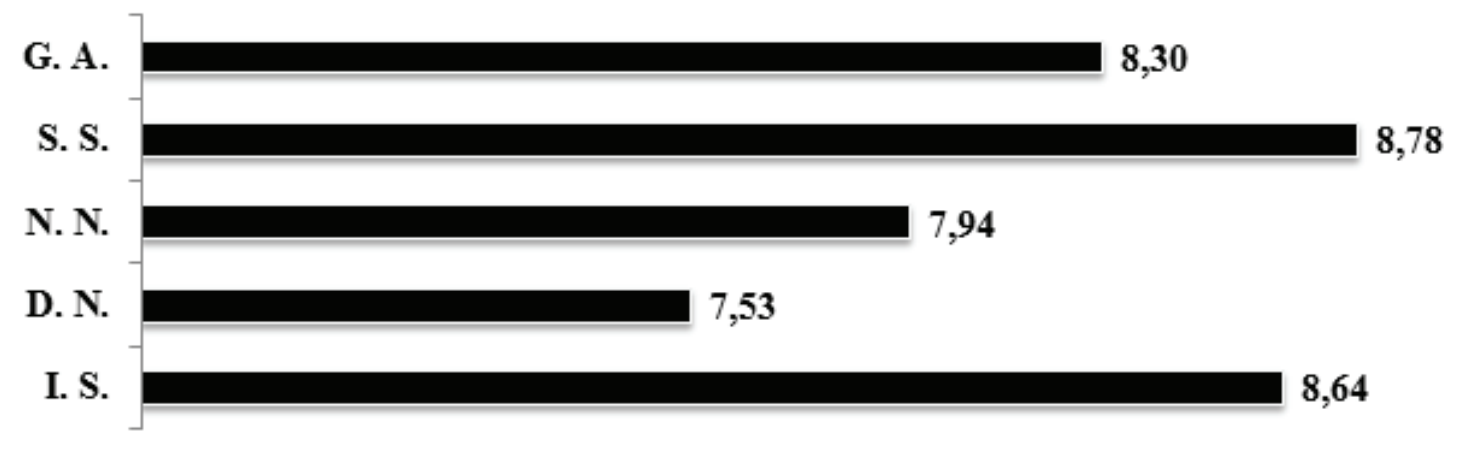

Figure 2. Average speeds of punches for the first measurement

\section{Results of second measurement in meters per second for the control group}

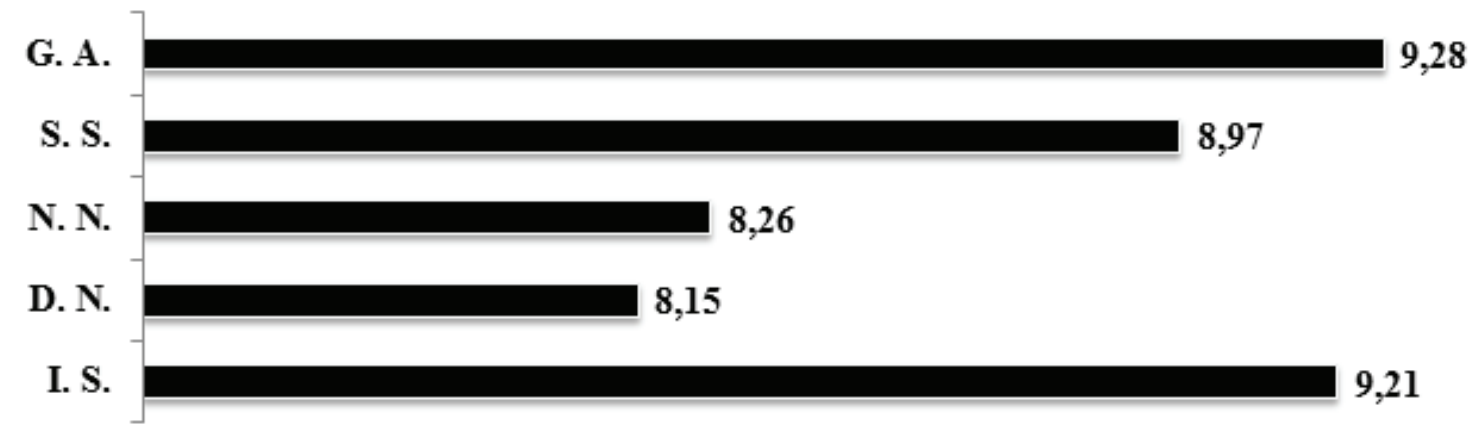

Figure 3. Average speeds of punches for the second measurement

After the first and the second measure- the test group. The results are shown in Figure ments, regarding the speed parameters of the 4 and Figure 5.

punch, we received the following results for

\section{Results of first measurement in meters per second for the test group}

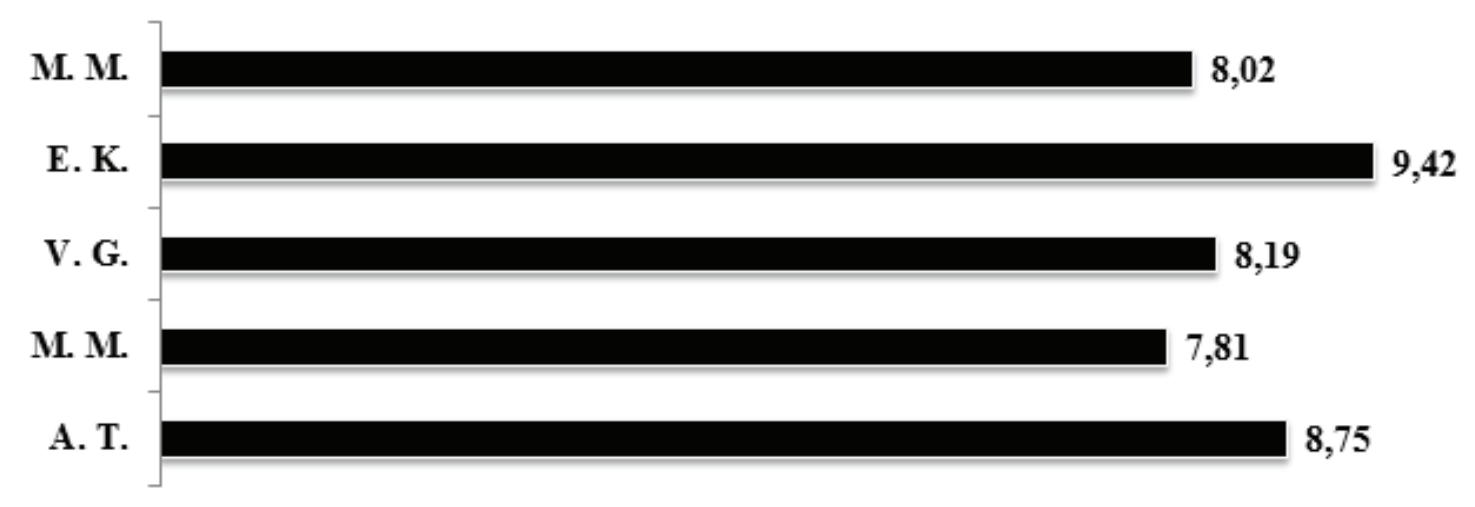

Figure 4. Average speeds of punches for the first measurement 


\section{Results of second measurement in meters per second for the test group}

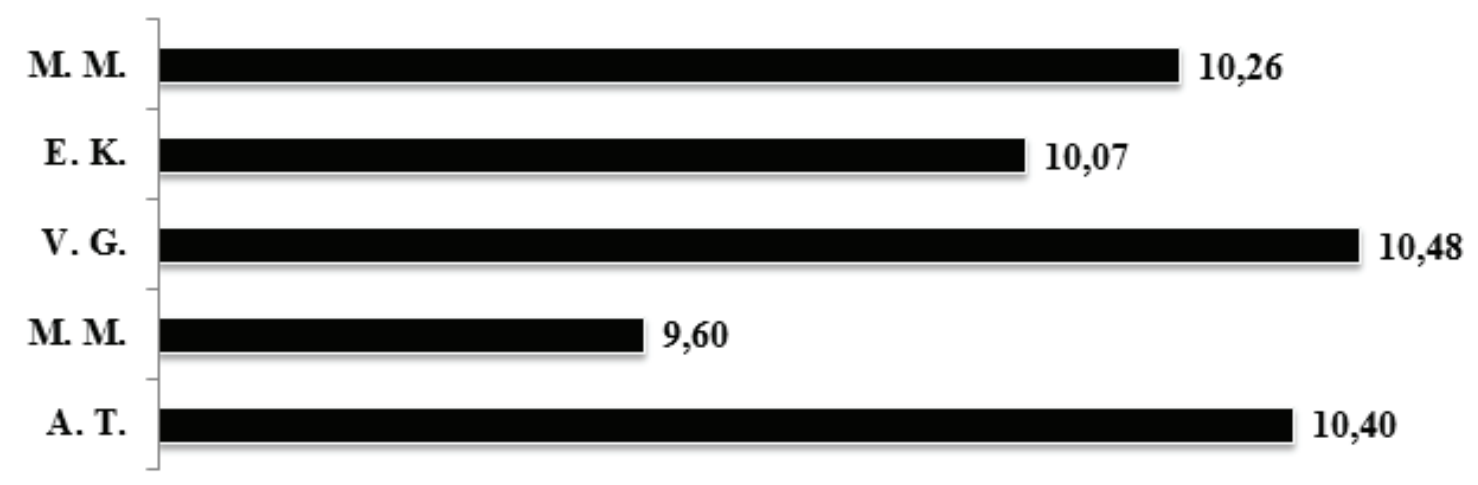

Figure 5. Average speeds of punches for the second measurement

Studying the speed of the Kizami Tsuki punch in karate is an important part of the training process and is connected to the correct execution of the punch as well as with the inability of the opponent to perform the respective defensive techniques. Therefore, it was important to us to prove that the methodology we created leads to improving the speed of the front-hand punch (Kizami Tsuki) in karate.
As a result of the training process we applied, indeed, we achieved improvements of the speed parameters of the punch. The results we received are provided in the materials to follow.

For the past period of training in the control group we observed no significant increases in the average maximum impact velocity by $0.53 \mathrm{~m} / \mathrm{s}$. These results are shown in Figure 6 .

\section{Generalized results of the two measurements in meters per second for the control group}

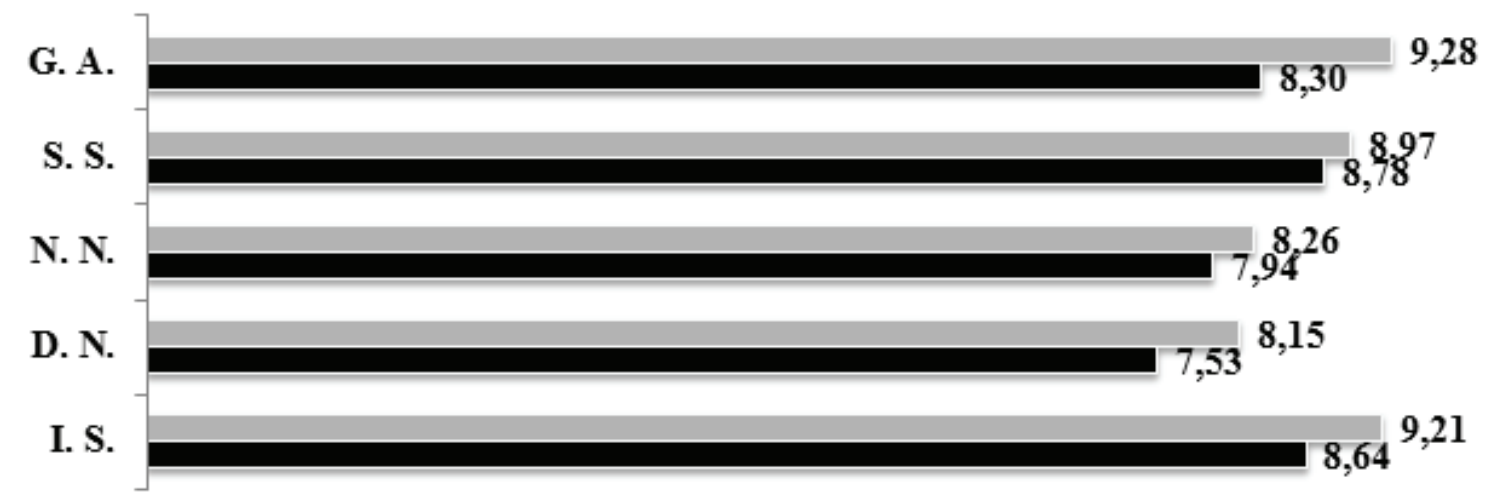

n Second measur ement

- First measur ement

Figure 6. Generalized results of the two measurements for the control group 
Figure 7 presents the generalized values of serve a significant improvement in the average speeds measured for the test group before and maximum punch velocity by $1,72 \mathrm{~m} / \mathrm{s}$. after applying the methodology. Here, we ob-

\section{Generalized results of the two measurements in meters per second for the test group}

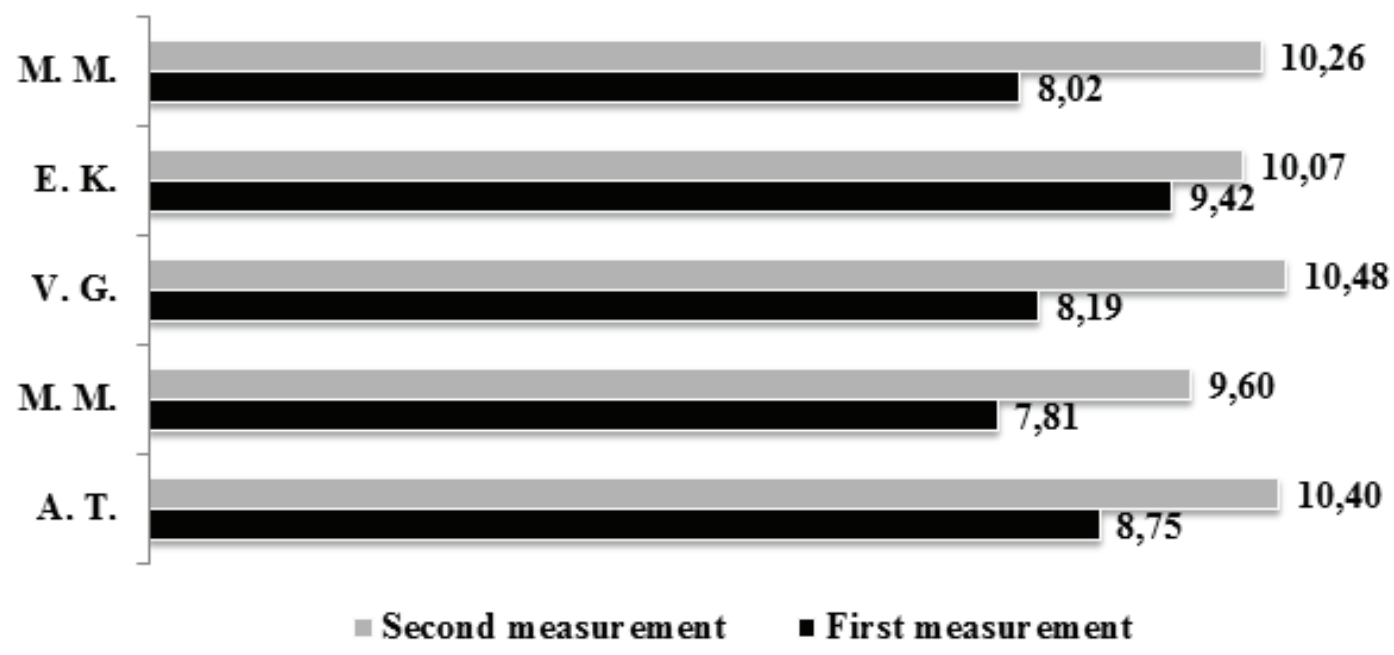

Figure 7. Generalized results of the two measurements for the test group

In order to illustrate the progress of the two the achieved results of the two groups for the groups more clearly, a comparison between period of training is presented in Figure 8.

\section{Generalized results after the training period}

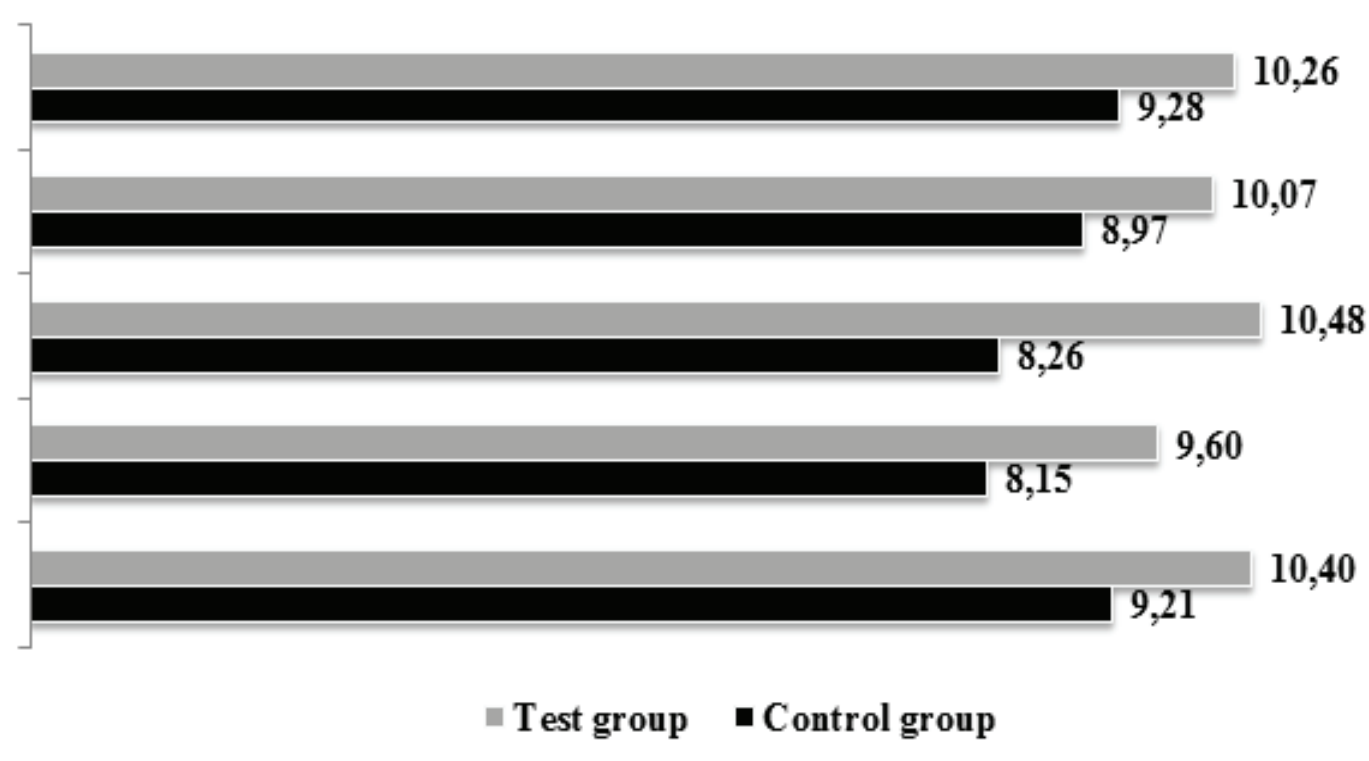

Figure 8. Generalized results after the training period 
As Table 4 indicates, the average speed of the test group is significantly higher than that of the control group. Respectively, the difference between the average maximum speeds of the two groups is $1,40 \mathrm{~m} / \mathrm{s}$ in favor of the group that used the experimental methodology.

Table 4. Statistical analysis

\begin{tabular}{ccc}
\hline Indicator/Group & Control Group & Test Group \\
\hline $\mathrm{X}$ & 8.773 & 10.162 \\
\hline $\mathrm{S}$ & 0.534 & 0.350 \\
\hline $\mathrm{V} \%$ & 6.086 & 3.448 \\
\hline
\end{tabular}

To calculate $\mathrm{V} \%$ (the coefficient of variation) we needed to calculate the standard deviation $\mathrm{S}$. The variation coefficient was obtained by ${ }^{V} V=\frac{S_{1}}{X}$ the following formula:

The coefficient for the control group was $6,086 \%$.

The coefficient for the test group is 3,488 $\%$.

It may be concluded that the survey is highly uniform, since V\% does not exceed 10$12 \%$.

\section{DISCUSSION}

After examination of several studies that affect the measurement of parameters of punch velocity, we determined what is the registered punch velocity measured by the other authors.

The linear velocity of the kizamizuki tchudan (jab punch in the trunk) was of 5,8 to $7,1 \pm 1,88$ $\mathrm{m} / \mathrm{s}$ (Marques, 2012), the kizami zuki without information about the target of the attack was of 5,7 to $9,8 \mathrm{~m} / \mathrm{s}$ (Diacu, 2013), the gyakuzuki tchudan (reverse punch) had linear velocity of 6,58 to $13 \mathrm{~m} / \mathrm{s}$ (Rathee, Magnes, Davis 2014), but the gyakuzuki without information about the target of the attack was of $14 \mathrm{~m} / \mathrm{s}$ (Cynarski, Wajs, Vencesbrito 2014). The oi zuki (lunge punch) was the last punch that the researcher detected the linear velocity. The oi zuki tchudan had lin- ear velocity of 5,83 $\pm 2,54$ to $10 \mathrm{~m} / \mathrm{s}$ (Marques, Gianino, 2010), but the oi zuki without information about the target of the attack was of 5,52 to $12,64 \mathrm{~m} / \mathrm{s}$ (Fernandes et.al., 2011). The best linear velocity was the gyaku zuki tchudan, the 2nd best linear velocity was the oi zuki tchudan and the last position was the kizami zuki tchudan.

The linear velocity of the punches (kizami zuki, gyakuzuki and oi zuki) in this systematic review was of 5,52 to $14 \mathrm{~m} / \mathrm{s}$. According to Ning (Ning et.al., 2011), the karate punch is very fast because this type of combat needs this motor capacity. The kung fu attack with technique similar to the punch, but with the open hand (yau-man in Chinese), the linear velocity was of 5,3 to $8,33 \mathrm{~m} / \mathrm{s}$ (Neto, Magini, Saba, 2007). Then, the result of the karate punch was better than the yau-man. The motive is the characteristics of the karate fight, in a few seconds the combat can finish with a precise attack (Tabben et.al., 2015). For example, Nakayama (Nakayama, 2012) informed that the Shotokan karate has the objective to finish the fight with an attack (ikkenhissatsu in Japanese). Therefore, the karateka usually trains the precision of the attack (Stevens, 2013)

In conclusion, we can state that, based on the literature related to the topic of the thesis, the speed of execution with the right arm in karate is one of the basic criteria for success- 
ful overcoming of the opponent. This gave us the good reason to do research on this subject.

\section{CONCLUSIONS}

The parameter analysis of the speed of the front-hand punch, as well as the application of the experimental methodology aimed at improving the speed of this punch have brought about observable positive results.

Improving the speed of punches in karate is of great significance in offensive techniques because attacks at higher speeds are harder to block by the opponent, which in turn, leads to winning the match.

Following the analysis of the front-hand punch speed (Kizami Tsuki), we observed that this speed is of great importance for the contender, who needs to choose the best attack during the sports match.

The improvement of the speeds between the attempts of both groups is credible, which proves that the speed measurement and the video analysis applied can be used in the sports training of karate practitioners and will contribute to improving their sports skills.

\section{REFERENCES:}

Barbanti, V. (2010). Treinamento esportivo: as capacidades motoras dos esportistas, Barueri: Manole, pp. 104-143.

Bishop, Mark (1989). Okinawan Karate: Teachers, Stylesand Secret Technique, A \& C Black, pp. 153 - 166.

Bogdanov, P., Ivanov Sv., (1972). Karate, MIF, Sofia.

Chaabène, H., Franchini, E., Miarka, B., Selmi, M., Mkaouer, B., and Chamari, K., (2014). Time-motion analysis and physiological responses to karate official combat sessions: is there a difference between winners and defeated karatekas?, International Journal of Sports Physiology and Performance, pp. 302-308.

Chaabène, H., Franchini, E., Sterkowicz, S., Tabben, M., Hachana, Y., Chamari, K. (2015). Physiological responses to karate specific activities. Sci Sports.

Cynarski, W., Wajs, W., Vencesbrito, A. (2014). Improving the movements of basic karate techniques with the use of motion capture and mathematical modeling. The concept of a research project. Journal of Martial Arts Anthropology, pp. 39-53.

Diacu, F. (2003). On the dynamics of karate, PIMS, pp. 9-11.

Fernandes, F., Wichi, R., Silva, V., Ladeira, A.,Ervilha, U. (2011). Biomechanical methods applied in martial arts studies. Journal of Morphological Science, pp. 141-144.

Franchini, E., Del Vecchio, F. (2011). Estudos emmodalida des esportivas de combate: "estado da arte". Revista Brasileira de Educação Física e Esporte, pp. 67-81.

Habersetzer R. (1998). Ko-Budo, Oruzhie Okinavii, Tirasop, Modus, pp. 230-254.

Higaonna, Morio, (1985). Traditional karate do Fundamental Techniques, Vol. 1, Japan Publications, pp. 17-20.

Marques Junior, N. (2012). Velocidade do soco e do chute do karatê: uma meta-análise. Lecturas: Educación Física y Deportes, pp. 1-12.

Marques Junior, N. (2013). Porque o soco causa maispontos do que o chute durante a luta de karatê? Conteúdo para prescrever o treino de karatêshotokan. Brazilian Journal of Exercise Physiology and Prescription, pp. 376-387.

Marques Junior, N. (2014). Scientific evidences about the fight of the shotokan karate of competition, Brazilian Journal of Exercise Physiology and Prescription, pp. 400-417.

Marques Junior, N. (2012). Velocidade do soco e do chute do karatê: uma meta-análise. 
Lecturas: EducaciónFísica y Deportes, pp. neering: Applications, Basis and Communica1-12 tions, pp. 75-82.

Marques Junior, N., Gianino, C. (2010).

Pinto Neto, O., Magini, M., Saba, M. Physics of karate: kinematics analysis of karate techniques by a digital movie camera. Latin-American Journal of Physics Education, pp. 32-34.

Marques Junior, N., Silva J. (2013). Filho. Treino de forza para o karateca do estiloshotokanespecialistano kumite. Revista Brasileira de Prescrição e Fisiologia do Exercício, pp. 506-533

Nakayama, M. (2012). O melhor do karatê 3 - kumite 1. $7^{\text {a }}$ ed., São Paulo: Cultrix, pp. 11-12.

Nakayma, M. (2012). O melhor do karate - fundamentos. vol. 2, 9a ed., São Paulo: Cultrix, pp. 108-109.

Ning, Y-L., Li, J-D., Lo, W-C., Huang, C-H., Chang, C-F., Hsieh, F-H., Lu, T-W. (2011). Patterns and consistency of muscle recruitment for karate jab, Biomedical Engi(2007). The role of effective mass and hand speed in the performance of kung fu athletes compared with nonpractitioners. Journal of Applied Biomechanics, pp.139-148.

Rathee, N., Magnes, J., Davis J., (2014). Kinematics of board breaking in karate usingvideo physics and human performance. European Scientific Journal, pp. 338-348.

Stevens, J. (2013). Trêsmestres do budo: Kano (judô), Funakoshi (karatê) e Ueshiba (aikido). 10 a ed., São Paulo: Cultrix, pp. 8081.

Tabben, M., Coquart, J., Chaabène, H., Franchini, E., Ghoul, N., Tourny, C. (2015). Time-motion, tactical and technical analysis in top-level karatekas according to gender, match outcome and weight categories. Journal of Sport Science, pp. 841-849.

\section{Corresponding author:}

Radoslav Penov

Department "Wrestling and Judo" National Sports Academy "Vassil Levski" Studentski grad, 21, Acad. Stefan Mladenov str. Sofia 1700, Bulgaria E-mail: fighters.nsa@abv.bg 